\title{
Interleukin-6 in pulmonary artery hypertension
}

https://doi.org/10.1515/labmed-2018-0196

Received December 11, 2018; accepted May 30, 2019; previously published online July 19, 2019

\begin{abstract}
Interleukin (IL)-6 is a pleiotropic cytokine, playing an important role in various pathological conditions, such as inflammatory, infectious, and neoplastic disorders. The casual relationship between IL-6 levels and development of pulmonary artery hypertension (PAH) has been elusive. Based on comprehensive retrieval of pertinent literature of recent two decades, this article aims to give an overview of the impact of IL- 6 on PAH development in view of both clinical and experimental aspects. Results showed that IL-6 was overexpressed in all types of PAH in both human and animal models. The elevated IL-6 levels were closely related to right ventricular (RV) dysfunction and predicted poor prognosis and mortality of PAH patients. Several IL-6-regulated signaling pathways including transforming growth factor (TGF)- $\beta$ /bone morphogenetic protein signaling pathway are involved in PAH development. IL-6 antagonizing agents are effective in ameliorating the symptoms and improving the RV function of PAH patients.
\end{abstract}

Keywords: cytokines; hypertension; interlukin-6; predictive value of tests; pulmonary; signaling transduction; therapeutics.

\section{Introduction}

Pulmonary artery hypertension (PAH) is a condition characterized by elevated pulmonary arterial pressure and resistance. According to the updated classification of the Fifth World Symposium on Pulmonary Hypertension (Nice, Francesca 2013), PAH is categorized into heritable, idiopathic, drug- and toxin-induced, and other disease (connective tissue disease, human immunodeficiency virus infection, portal hypertension, congenital heart

\footnotetext{
*Correspondence: Shi-Min Yuan, MD, PhD, Department of Cardiothoracic Surgery, The First Hospital of Putian, Teaching Hospital, Fujian Medical University, 389 Longdejing Street, Chengxiang District, Putian 351100, Fujian Province, P.R. China, Phone: +86 594 6923117, E-Mail: shiminyuan@126.com
}

disease, or schistosomiasis)-associated types [1]. The typical pathological changes of the pulmonary vasculature in $\mathrm{PAH}$ patients were vasoconstriction, pulmonary vascular proliferation, apoptosis, and angiogenesis [2, 3]. It has been proved that the pathogenesis of $\mathrm{PAH}$ and the pulmonary vascular remodeling is involved in genetic predispositions, dysregulated cellular signaling pathways, and altered cytokine expressions [4]. The genetic backgrounds of $\mathrm{PAH}$ in children with regard to transforming growth factor (TGF)- $\beta$ superfamily genes have been described [5]. Interleukin (IL)-6 is a pleiotropic cytokine in charge of immune regulation, hematopoiesis, inflammation, and oncogenesis [5]. It has been proposed that casual relations may exist between pathogenesis of $\mathrm{PAH}$ and excessive production of IL-6 [6]. However, the implications of upregulated IL- 6 in the development of PAH have not been sufficiently elucidated. The purpose of this article is to give an overview of the impact of IL- 6 on PAH development in view of both clinical and experimental aspects.

\section{Clinical research}

\section{IL-6 profiles in PAH}

IL-6 levels were found to be elevated in patients with PAH $[7,8]$ and animal models of PAH [9, 10]. Selimovic et al. [11] reported that IL-6 levels were significantly higher in PAH patients than in controls (3.98 vs. $0.7 \mathrm{pg} / \mathrm{mL}$; $\mathrm{p}<0.001$ ). However, they did not find any difference in IL-6 levels detected in blood samples taken either from the right atrium or from the pulmonary artery between patients with idiopathic PAH and those with collagen vascular disease-associated PAH (Figure 1) [11]. A prospective review including 37 children with congenital heart defect-related $\mathrm{PAH}, 21$ children with congenital heart defects only, and 22 healthy children revealed that serum IL- 6 levels were significantly higher in children with congenital heart defect-related PAH than in other group patients (Figure 2) [9]. Kalambokis et al. [10] detected serum IL-6 levels in patients with cirrhosis, with and without PAH: 15 cirrhosis patients with a pulmonary vascular resistance (PVR) 


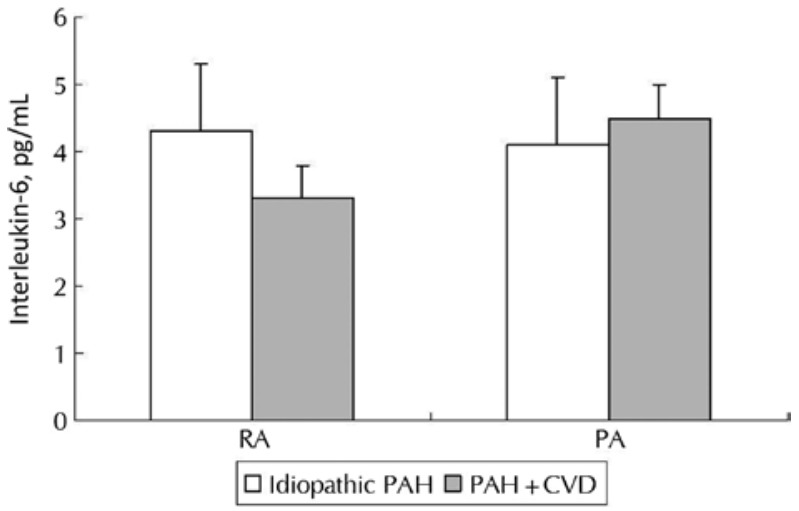

Figure 1: No difference was found in interleukin- 6 levels between patients with idiopathic pulmonary artery hypertension (PAH) and those with PAH and collagen vascular diseases (CVD) [11]. $\mathrm{PA}$, pulmonary artery; RA, right atrium.

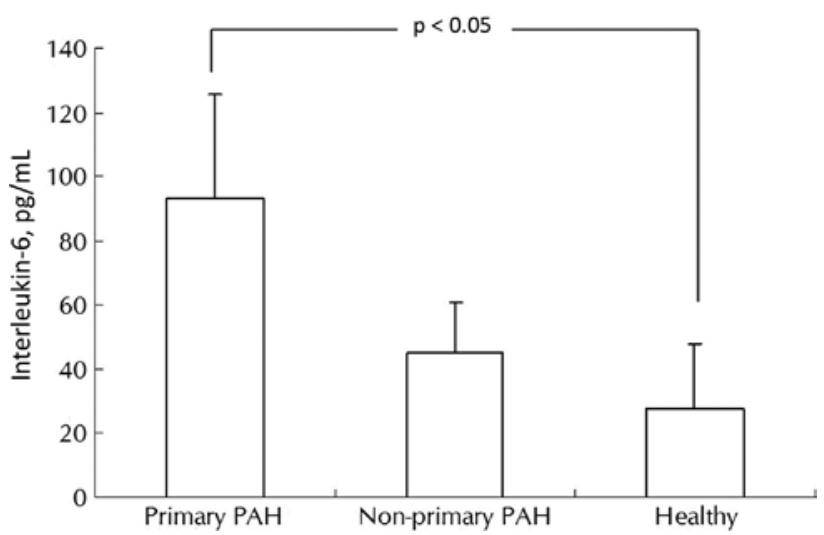

Figure 2: Serum interleukin-6 levels were significantly higher in the children with congenital heart defect-related pulmonary artery hypertension (PAH) [9].

$<120 \mathrm{dyn} \cdot \mathrm{s} / \mathrm{cm}^{5}$ vs. 8 patients with a PVR $>120 \mathrm{dyn} \cdot \mathrm{s} / \mathrm{cm}^{5}$. As a result, serum IL-6 levels were higher in those with a higher PVR compared with those with a lower PVR (43.2 \pm 10.7 vs. $16.1 \pm 3.7 \mathrm{pg} / \mathrm{mL} ; \mathrm{p}=0.008$ ). Zorzanelli et al. [12] compared serum cytokine levels between pediatric patients with PAH and those without. They found that serum IL-6 levels remarkably decreased in proportion to a significant increase of the pulmonary-to-systemic flow ratio and improvement of peripheral oxygen saturation.

Several studies disclosed that patients with idiopathic PAH had consistently elevated IL-6 levels in blood circulation $[7,11]$ and in the lung tissues [13]. In patients with systemic lupus erythematosus, mixed connective tissue disease, or systemic sclerosis, an elevated serum IL-6 was noted in patients with PAH than in those without [14]. In addition, elevated serum IL-6 was reported in patients with polyneuropathy, organomegaly, endocrinopathy, monoclonal gammopathy, and skin changes (POEMS) syndrome owing to the complicated PAH [15].

Heresi et al. [16] recruited in their study $76 \mathrm{PAH}$ patients, including 40 idiopathic, 10 heritable, 19 connective tissue disease-associated, and seven congenital heart defect-associated types of PAH. Targeted therapies were applied in 63 of these PAH patients, 32 of whom received parenteral prostacyclin, and their IL-6 level was 3.82 (range, 1.79-9.87) pg/mL. Furuya et al. [5] reported that a female patient with multicentric Castleman's disease associated with severe $\mathrm{PAH}$ and a significantly elevated serum IL-6 of $41.8 \mathrm{pg} / \mathrm{mL}$ was treated with tocilizumab, an IL-6 antagonizing immunosuppressive agent, at a dose of $8 \mathrm{mg} / \mathrm{kg}$ every 2 weeks. Tocilizumab was proved to be a promising agent for ameliorating the patient's symptoms including low-grade fever, anorexia, and fatigue. A 3-month tocilizumab treatment led to a gradually decreased serum IL-6 level (Figure 3) and decreased pulmonary artery pressure, PVR, and right atrial pressure as well [5].

\section{Casual relations between IL-6 and PAH}

IL-6 levels in PAH patients were closely related to PVR [10]. Increased serum IL-6 levels are associated with greater symptomatic burden and increased mortality in PAH, and this was interpreted as the adverse effects of IL-6 on right ventricular (RV) function [17]. Prins et al. [17] analyzed the relationship between IL-6 levels and RV function in 40 PAH patients, and found that patients with an increased IL-6 level had remarkable RV dysfunction, impaired RVpulmonary artery coupling, higher right atrial pressures,

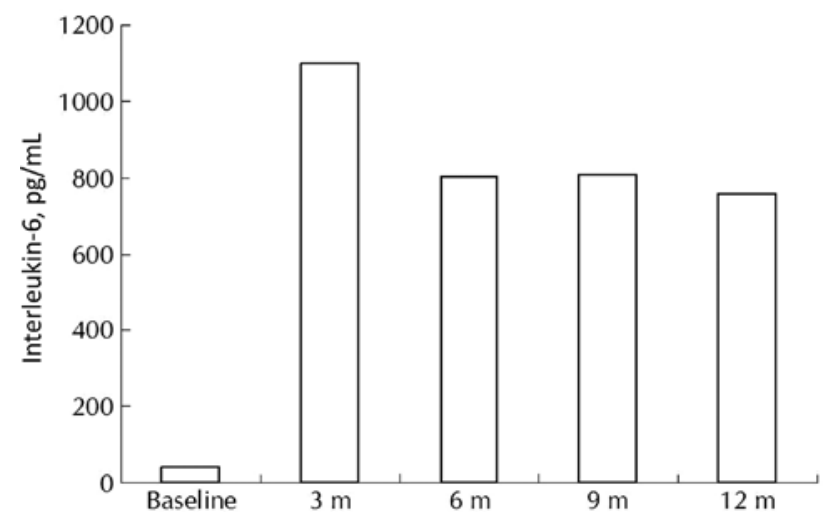

Figure 3: Serum interleukin-6 decreased gradually after a 3-month treatment with tocilizumab in patient with multicentric Castleman's disease associated with secondary pulmonary artery hypertension [5]. $\mathrm{m}$, months. 
reduced cardiac index, and lower stroke volume in comparison to those with a lower IL-6 level. However, IL-6 did not correlate with mean pulmonary artery pressure, PVR, and pulmonary arterial compliance [17]. Oz-Tuncer et al. [9] demonstrated that serum IL-6 levels negatively correlated with systemic flow $(r=-0.572, \mathrm{p}=0.021)$, positively with systemic vascular resistance $(r=0.774, \mathrm{p}=0.001)$, and positively with pulmonary wedge pressure $(r=0.796$, $\mathrm{p}=0.006)$ in PAH patients. Other authors $[8,18]$ also observed a relationship between elevated IL-6 levels and quality of life-related symptoms including pain, fatigue, anxiety, and depression.

\section{Predictive values of IL-6}

In a multivariate analysis, increased IL-6 levels predicted mortality, and elevated IL-6 levels in PAH patients were taken as an independent predictor of adverse outcome [11]. Soon et al. [8] detected serum cytokines including IL-6, and disclosed an elevated IL-6 in patients with idiopathic PAH, which correlated closely with the severity of disease and mortality [8]. Heresi et al. [16] found that both IL- 6 and high sensitivity C-reactive protein (CRP) were univariate predictors of mortality. A cut-off value of IL- $6 \geq 4.7 \mathrm{pg} / \mathrm{mL}$ had a sensitivity of $86 \%$ and a specificity of $72 \%$, predicting a 9 -fold increase of mortality [16]. The analysis showed that combined 6-min walking distance (cut-off: $450 \mathrm{~m}$ ), right atrial pressure (cut-off: $8 \mathrm{mmHg}$ ), and IL-6 (cut-off: $5.6 \mathrm{pg} / \mathrm{mL}$ ) were a sensitive indicator of patient survival. Humbert et al. [7] in a proinflammatory cytokine study in 29 severe PAH patients illustrated that serum IL-6 was significantly higher in these patients than in patients with $\mathrm{PAH}$ secondary to chronic obstructive pulmonary disease (COPD) $(118 \pm 36 \mathrm{pg} / \mathrm{mL}$ vs. $3 \pm 1 \mathrm{pg} / \mathrm{mL}$, $\mathrm{p}<0.001)$ or with idiopathic PAH than in controls $(118 \pm 36 \mathrm{pg} / \mathrm{mL}$ vs. $3 \pm 1 \mathrm{pg} / \mathrm{mL}, \mathrm{p}<0.001)$ (Figure 4). In general, IL-6 is attributable to the pathogenesis of PAH of different types. However, the distinctive effects of IL-6 on each type of PAH warrant further elucidations.

\section{Experimental research}

Endogenous IL-6 mediates hypoxic PAH and lung inflammatory process [19]. IL-6 overexpression in the transgenic mice led to spontaneous development of pulmonary vascular remodeling and PAH [20]. A lung-specific overexpression of IL-6 in mice resulted in increased PVR and pathological changes similar to those observed in $\mathrm{PAH}$

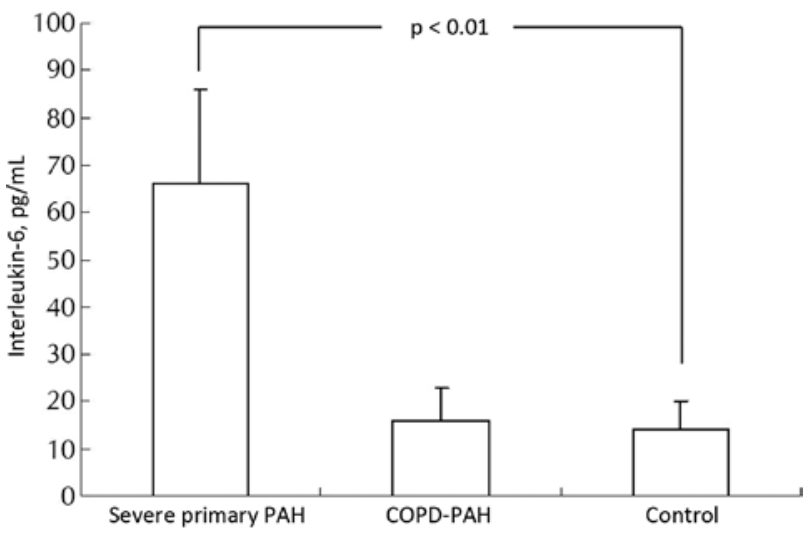

Figure 4: Patients with severe idiopathic pulmonary artery hypertension (PAH) had higher serum interleukin-6 levels than controls [7].

patients [6]. PAH shows an inflammatory phenotype of macrophage $\mathrm{CD}^{+} 8^{+}$infiltration in the lung vasculature associated with reduced $\mathrm{T}$ cells and dysregulated natural killer cells [17]. Pulmonary IL-6 production is increased in experimental PAH and is thought to reflect increased production by both inflammatory and vascular cells [19]. There is strong evidence that IL- 6 overproduction triggers PAH and lack of IL-6 in knockout mice prevents PAH [6, 17, 19]. Experimental studies revealed that IL-6 overexpression induced muscularization of the pulmonary vascular bed. Knockout of IL-6 leads to partial protection against chronic hypoxia-induced PAH [19]. In lung-specific IL6-overexpressing transgenic mice $\mathrm{Tg}+$ mice, the number of the elastic lamina and the percentage of medial wall thickness of the main pulmonary artery branch were increased in comparison to the wild-type $\mathrm{Tg}$ - control under either normoxic or hypoxic conditions. IL-6 overexpression also induced arteriolar neointimal occlusive lesions [6]. Steiner et al. [6] found, in an experiment of pulmonary remodeling in $\mathrm{Tg}+$ in comparison to $\mathrm{Tg}$ - controls, partial $(27 \pm 5 \%)$ or complete occlusion ( $4 \pm 2 \%$ ) of the arterioles in $\mathrm{Tg}+$ mice, but patent arterioles and unthickened intima in the lung tissues of Tg- control mice. They also observed that IL- 6 also induced distal pulmonary vascular wall endothelial cellular growth and proliferation represented by an elevated vascular endothelial growth factor (VEGF) receptor 2 (VEGFR2) expression in pulmonary artery endothelial cells of $\mathrm{Tg}+$ mice and minimal expression of VEGFR2 in $\mathrm{Tg}$ - mice. Savale et al. [19] proved, in hypoxia exposure of IL- $6^{+/+}$mice, marked increases of IL- 6 messenger RNA (mRNA) and protein in the first week, with positive IL-6 immunostaining in the pulmonary vascular walls. Lung IL-6 receptor and glycoprotein 130 (the IL- 6 signal transducer) mRNA levels increased after 1- and 2-week hypoxic 
insult. Transgenic overexpression of a mutant bone morphogenic protein (BMP) receptor 2 (BMPR2) increases IL-6 levels in the lungs and renders mice susceptible to PAH [21]. IL-6 showed an acute negative inotropic effect on isolated hamster and chicken left ventricular cardiomyocytes mediated by nitric oxide overproduction [22, 23]. Furthermore, neonatal rat ventricular cardiomyocytes cultured in the presence of IL- 6 revealed reduced mRNA and protein levels of SERCA2a, a sarcoplasmic endoplasmic reticulum calcium-adenosine triphosphatase found in the membrane of the sarcoplasmic reticulum [24].

IL-6 level is an independent predictor of RV dilation in the Multi-Ethnic Study of Atherosclerosis (MESA)-RV study [25]. Hagen et al. [21] discovered in in vitro and in vivo studies IL-6 upregulation in both transgenic mice and in cultured human pulmonary artery smooth muscle cells. An experimental study demonstrated that 2-week hypoxiaexposed IL-6-deficient (IL-6 ${ }^{-1}$ ) mice showed decreased RV systolic pressure, RV hypertrophy, and number and medial thickness of muscular pulmonary vessels, and less inflammatory cell recruitment in the lungs, compared with hypoxic wild-type IL- $6^{+/+}$mice, whereas hypoxic IL- $6^{+/+}$mice had increased mRNA and protein levels of IL-6 within the first week, with positive IL-6 immunohistochemical stainings in the pulmonary vascular walls [19].

Several animal models of PAH, including chronic hypoxia [19] and monocrotaline treatment [18], are also associated with an increased production of IL-6. Moreover, daily subcutaneous injection of recombinant IL-6 in rats induced medial thickening of the pulmonary arterioles, leading to PAH [26]. Young male SV129 mice with a 3-week hypoxic exposure receiving SU5416, a VEGFR inhibitor, 3 times a week, showed pathological changes of characteristic PAH, including concentric neointimal wall thickening, plexogenic lesions, recruitment of macrophages, and distal arteriolar wall muscularization [27]. In the arteriolar adventitia, IL-6 level was increased with stronger inflammatory cell recruitment, and in lung tissue lysates and arteriolar media, endothelin (ET)-1 and ET receptor A were upregulated. The results were in line with the increasing ET-1 and decreasing ET receptor B levels in the recombinant human IL- 6 provoked endothelial cells, indicating that IL-6 regulates ET signaling in PAH progression [27].

Experiments on C57BL6 mice at 8 weeks of age exposed to $10 \%$ oxygen hypoxia for 4 weeks resulted in upregulation of IL-6 in the lung tissues. After $2 \mathrm{mg}$ of MR16-1 or rat immunoglobulin G was given to the animals by intravenous injection just before the insult and also hypoxic animals by intraperitoneal injection with $0.5 \mathrm{mg}$ of MR16-1, a monoclonal antibody to mouse IL-6 receptor, or rat immunoglobulin G once a week, MR16-1 showed

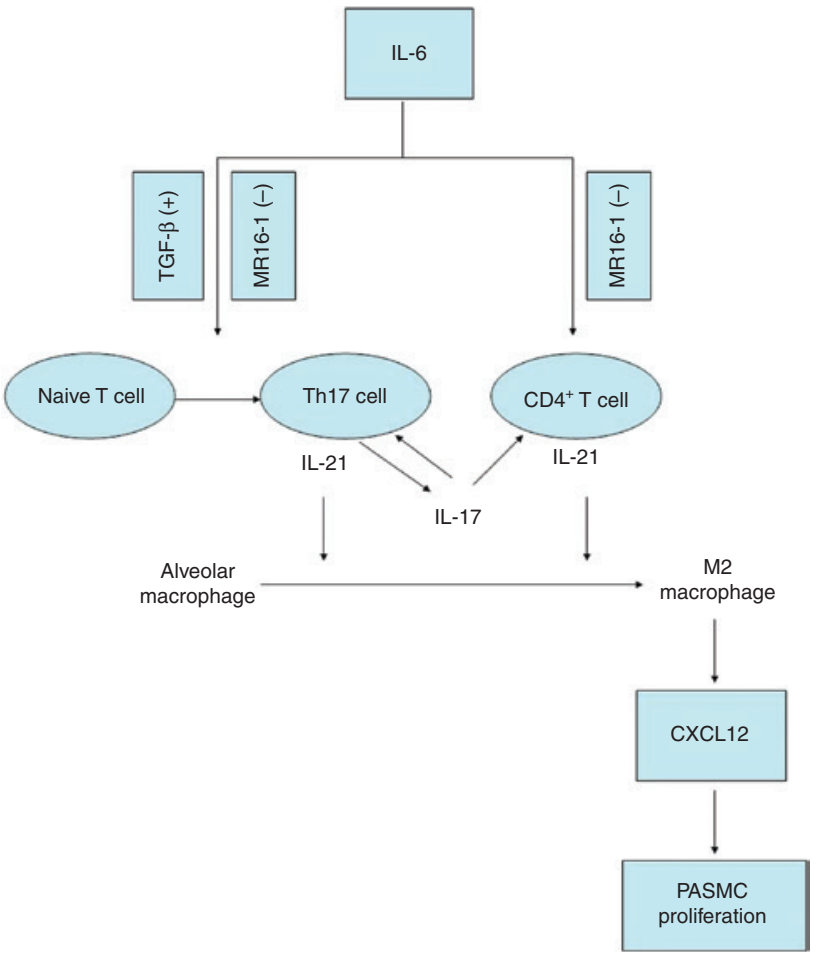

Figure 5: Schematic illustration of the development of pulmonary artery hypertension (PAH) through the interleukin (IL)-6/Th17/IL-21signaling axis [29].

PASMC, pulmonary artery smooth muscle cell; TGF, transforming growth factor.

much better RV function than control in terms of improved RV systolic pressure and RV hypertrophy, and significantly decreased medial wall thickness of the pulmonary vessels. It illustrated that the antagonism of IL-6 signaling might become a promising strategy for the treatment of PAH [28]. Hashimoto-Kataoka et al. [29] conducted an experiment in mice, and found that IL- 6 blockade by the monoclonal anti-IL-6 receptor antibody, MR16-1, ameliorated hypoxia-induced PAH and prevented the hypoxiainduced accumulation of Th17 cells and M2 macrophages in the lungs. In addition, dexamethasone was observed to effectively reverse the pulmonary IL-6 overexpression and IL-6-expressing adventitial inflammatory cell infiltration in monocrotaline-induced PAH rats [30]. PAH develops via the IL-6/Th17/IL-21-signaling axis incorporated by TGF- $\beta$ and MR16-1 (Figure 5) [29].

\section{Discussion}

IL-6 overexpression increases pulmonary artery pressure and RV hypertrophy. In animal models, IL-6 regulates many pathways of inflammatory disease 
progression, mimicking the pathology of human PAH [31]. IL-6 contributes to the development and progression of cirrhosis-associated PAH. IL- 6 may also cause vasoconstriction via inhibition of nitric oxide-mediated relaxation, or via the adrenergic or muscarinic receptor pathway [10]. Moreover, IL-6 may promote thrombosis of the lung microarteries [10]. Perivascular infiltration of inflammatory cells, consisting of T cells, B cells, and macrophages, are often present in the affected pulmonary arteries of PAH patients, suggesting that cytokines and growth factors are released from the inflammatory cells and involved in the proliferation of the pulmonary artery smooth muscle and endothelial cells [32]. By this means, a lung-specific overexpression of IL- 6 in mice resulted in increased PVR and pathological changes similar to those in PAH patients [33]. IL-6 promotes proliferation of smooth muscle and endothelial cells, thereby dysregulating cellular growth and apoptosis, resulting in pulmonary vascular remodeling in PAH, potentially mediating proliferative, prosurvival, and anti-apoptotic processes. By this means, IL- 6 brings about vascular smooth muscle cell proliferation through upregulation of VEGF and its receptor VEGFR2 [32]. In scleroderma-associated PAH, predominant obliterative-concentric lesions with fewer plexiform lesions were observed [34]. Eddahibi et al. [35] reported, based on a study in 50 patients with COPDrelated PAH, the IL-6 G/G polymorphism (-174G/C) correlated with a higher level of IL-6 among patients with COPD but not among control subjects. Patients carrying the IL-6 GG genotype showed higher serum levels of IL-6 and higher pulmonary artery pressure than those carrying the CC or CG genotype. These results indicated that the inflammatory cytokine IL-6 might contribute to PAH in COPD and that IL- 6 gene polymorphism endorses susceptibility to patients with PAH secondary to COPD. BMPR2 gene mutation might boost cell division and prevent cell death, leading to pulmonary vascular remodeling, and one-fifth of individuals with a BMPR2 gene mutation might progress into PAH [36]. Thus, BMPR2 gene mutations constitute the background of the pathogenesis of heritable PAH [37]. Loss of BMPR2 causes proliferation of pulmonary artery smooth muscle cells in response to TGF- $\beta_{1}$ and BMP2 [38].

It is well-known that the TGF- $\beta / B M P$ signaling pathway adjusts vascular smooth muscle and endothelial cell growth by inhibiting excessive proliferations. IL-6-induced arteriopathic changes are accompanied by activation of growth factors, proproliferative kinase extracellular signal-regulated kinase, proproliferative transcription factors, and the antiapoptotic proteins. [6]. These findings suggest that IL-6 promotes the development and progression of pulmonary vascular remodeling and PAH through proproliferative antiapoptotic mechanisms [6].

Angiopoietin (Ang)-1-Tie2 pathway is essential for both embryonic and postnatal angiogenesis and involves in a protective action on endothelial cells by suppressing inflammation and apoptosis [39]. An increased Ang-1-Tie2 activity may play a critical role during PAH progression [40]. Measures to increase Ang-1-Tie2 signaling may protect against lung endothelial cell injury and development of PAH [40]. During the development of PAH with vascular remodeling, expressions of Ang-1, Tie2, and VEGF in the pulmonary arteries significantly decreased, and Tie2 receptor was inactivated in the lung tissues. Stimulation of macrophage Tie2 with Ang-1 promotes tumor necrosis factor-induced proinflammatory cytokine and chemokine expressions [41]. However, Ang-3, an endogenous antagonist of Ang-1, was upregulated in the intima under a hypoxic condition. As both Ang-1-Tie2 and VEGF promote angiogenesis and vascular survival, and play a protective role in the adaptation of microvascular changes during the onset of $\mathrm{PAH}$, the downregulation of both Ang1-Tie2 and VEGF and upregulation of Ang-3 appear to be associated with vascular rarefaction and development of hypoxic PAH [42].

The terminal elimination half-lives of IL-6 was $15.5 \mathrm{~h}$. The results suggested that IL- 6 synthesized in response to inflammatory stimulation was rapidly eliminated [43]. IL-6 in plasma is very unspecific and volatile, and several investigators have identified this cytokine to be involved in the pathogenesis of various diseases [44]. PAH patients often have concurrent RV dysfunction, with the late condition being a co-factor of inducing the upregulation of IL-6. In patients with connective tissue disorder-related PAH, both $\mathrm{PAH}$ and the connective tissue disorders per se stimulate IL-6 release [5, 14, 45]. In human immunodeficiency virus-infected patients, glycoprotein 120 activates the monocytes and macrophages to release ET and IL-6 [46]. Inflammation in human immunodeficiency virus infection is due to the lack of gut $\mathrm{CD}^{+} \mathrm{T}$ cell restoration, which favors lipopolysaccharide translocation and chronic systemic IL-6 overproduction [46]. Therefore, the diagnostic value of IL- 6 can be less specific when $\mathrm{PAH}$ is in association with inflammatory disorders. Moreover, as indicated by Chaouat et al. [47] in a multiple stepwise regression analysis, with mean pulmonary artery pressure as the dependent variable, three independent variables, including pulmonary wedge pressure, partial pressure of oxygen, and IL-6, contributed to mean pulmonary artery pressure by $25 \%, 15 \%$, and $9 \%$, respectively. 


\section{Conclusions}

Elevated IL-6 levels in PAH patients are associated with RV dysfunction and impaired RV-pulmonary artery coupling, and predicted poor prognosis and mortality of PAH patients. IL-6 is thus a key factor leading to PAH and vascular remodeling process. Accordingly, IL-6 antagonizing agents are effective in ameliorating the symptoms and improving the RV function of PAH patients by their antiproliferative and reversing vascular remodeling effects.

Author contributions: All the authors have accepted responsibility for the entire content of this submitted manuscript and approved submission.

Research funding: None declared.

Employment or leadership: None declared.

Honorarium: None declared.

Competing interests: The funding organization(s) played no role in the study design; in the collection, analysis, and interpretation of data; in the writing of the report; or in the decision to submit the report for publication.

\section{References}

1. Galiè N, Simonneau G. The Fifth World Symposium on Pulmonary Hypertension. J Am Coll Cardiol 2013;62:1-3.

2. Nie X, Tan J, Dai Y, Mao W, Chen Y, Qin G, et al. Nur77 downregulation triggers pulmonary artery smooth muscle cell proliferation and migration in mice with hypoxic pulmonary hypertension via the Axin2- $\beta$-catenin signaling pathway. Vascul Pharmacol 2016;87:230-41.

3. Xu W, Erzurum SC. Endothelial cell energy metabolism, proliferation, and apoptosis in pulmonary hypertension. Compr Physiol 2011;1:357-72.

4. Jonas K, Magoń W, Waligóra M, Seweryn M, Podolec P, Kopeć G. High-density lipoprotein cholesterol level and pulmonary artery vasoreactivity in patients with idiopathic pulmonary arterial hypertension. Pol Arch Intern Med 2018;128:440-6.

5. Furuya Y, Satoh T, Kuwana M. Interleukin-6 as a potential therapeutic target for pulmonary arterial hypertension. Int J Rheumatol 2010;2010:720305.

6. Steiner MK, Syrkina OL, Kolliputi N, Mark EJ, Hales CA, Waxman $A B$. Interleukin-6 overexpression induces pulmonary hypertension. Circ Res 2009;104:236-44, 28p following 244.

7. Humbert M, Monti G, Brenot F, Sitbon O, Portier A, GrangeotKeros $L$, et al. Increased interleukin- 1 and interleukin- 6 serum concentrations in severe primary pulmonary hypertension. Am J Respir Crit Care Med 1995;151:1628-31.

8. Soon E, Holmes AM, Treacy CM, Doughty NJ, Southgate L, Machado RD, et al. Elevated levels of inflammatory cytokines predict survival in idiopathic and familial pulmonary arterial hypertension. Circulation 2010;122:920-7.
9. Oz-Tuncer G, Olgunturk R, Pektas A, Cilsal E, Kula S, Oguz DA, et al. The role of inflammatory biomarkers in CHD-associated pulmonary hypertension in children. Cardiol Young 2017;27:255-60.

10. Kalambokis GN, Mouzaki A, Rodi M, Pappas K, Korantzopoulos $P$, Tsianos EV. Serum interleukin 6 levels and cirrhosis-associated pulmonary hypertension. Angiology 2011;62:344-5.

11. Selimovic N, Bergh CH, Andersson B, Sakiniene E, Carlsten $\mathrm{H}$, Rundqvist B. Growth factors and interleukin- 6 across the lung circulation in pulmonary hypertension. Eur Respir J 2009;34:662-8.

12. Zorzanelli L, Maeda N, Clavé M, Thomaz A, Galas F, Rabinovitch $M$, et al. Relation of cytokine profile to clinical and hemodynamic features in young patients with congenital heart disease and pulmonary hypertension. Am J Cardiol 2017;119:119-25.

13. Tuder RM, Chacon M, Alger L, Wang J, Taraseviciene-Stewart L, Kasahara Y, et al. Expression of angiogenesis-related molecules in plexiform lesions in severe pulmonary hypertension: evidence for a process of disordered angiogenesis. J Pathol 2001;195:367-74.

14. Yoshio T, Masuyama JI, Kohda N, Hirata D, Sato H, Iwamoto $M$, et al. Association of interleukin 6 release from endothelial cells and pulmonary hypertension in SLE. J Rheumatol 1997;24:489-95.

15. Lesprit P, Godeau B, Authier FJ, Soubrier M, Zuber M, Larroche $\mathrm{C}$, et al. Pulmonary hypertension in POEMS syndrome: a new feature mediated by cytokines. Am J Respir Crit Care Med 1998;157(3 Pt 1):907-11.

16. Heresi GA, Aytekin M, Hammel JP, Wang S, Chatterjee S, Dweik RA. Plasma interleukin- 6 adds prognostic information in pulmonary arterial hypertension. Eur Respir J 2014;43:912-4.

17. Prins KW, Archer SL, Pritzker M, Rose L, Weir EK, Sharma A, et al. Interleukin-6 is independently associated with right ventricular function in pulmonary arterial hypertension. J Heart Lung Transplant 2018;37:376-84.

18. Bhargava A, Kumar A, Yuan N, Gewitz MH, Mathew R. Monocrotaline induces interleukin- 6 mRNA expression in rat lungs. Heart Dis 1999;1:126-32.

19. Savale L, Tu L, Rideau D, Izziki M, Maitre B, Adnot S, et al. Impact of interleukin-6 on hypoxia-induced pulmonary hypertension and lung inflammation in mice. Respir Res 2009;10:6.

20. Ferrari R, Tanni SE, Caram LM, Corrêa C, Corrêa CR, Godoy I. Three-year follow-up of interleukin 6 and C-reactive protein in chronic obstructive pulmonary disease. Respir Res 2013;14:24.

21. Hagen M, Fagan K, Steudel W, Carr M, Lane K, Rodman DM, et al. Interaction of interleukin- 6 and the BMP pathway in pulmonary smooth muscle. Am J Physiol Lung Cell Mol Physiol 2007;292:L1473-9.

22. Finkel MS, Oddis CV, Jacob TD, Watkins SC, Hattler BG, Simmons RL. Negative inotropic effects of cytokines on the heart mediated by nitric oxide. Science 1992;257:387-9.

23. Kinugawa K, Takahashi T, Kohmoto O, Yao A, Aoyagi T, Momomura S, et al. Nitric oxide-mediated effects of interleukin- 6 on $\left[\mathrm{Ca}^{2+}\right]$ and cell contraction in cultured chick ventricular myocytes. Circ Res 1994;75:285-95.

24. Villegas S, Villarreal FJ, Dillmann WH. Leukemia inhibitory factor and interleukin-6 downregulate sarcoplasmic reticulum $\mathrm{Ca}^{2+}$ ATPase (SERCA2) in cardiac myocytes. Basic Res Cardiol 2000;95:47-54.

25. Harhay MO, Tracy RP, Bagiella E, Barr RG, Pinder D, Hundley WG, et al. Relationship of CRP, IL-6, and fibrinogen with right 
ventricular structure and function: the MESA-Right Ventricle Study. Int J Cardiol 2013;168:3818-24.

26. Miyata M, Ito M, Sasajima T, Ohira H, Kasukawa R. Effect of a serotonin receptor antagonist on interleukin-6-induced pulmonary hypertension in rats. Chest 2001;119:554-61.

27. Van Hung T, Emoto N, Vignon-Zellweger N, Nakayama K, Yagi K, Suzuki Y, et al. Inhibition of vascular endothelial growth factor receptor under hypoxia causes severe, human-like pulmonary arterial hypertension in mice: potential roles of interleukin- 6 and endothelin. Life Sci 2014;118:313-28.

28. Kataoka TH. Abstract 12506: blockade of interleukin-6 signaling prevents hypoxia induced pulmonary hypertension in mice. Circulation 2013;128:A12506.

29. Hashimoto-Kataoka T, Hosen N, Sonobe T, Arita Y, Yasui T, Masaki T, et al. Interleukin-6/interleukin-21 signaling axis is critical in the pathogenesis of pulmonary arterial hypertension. Proc Natl Acad Sci U S A 2015;112:E2677-86.

30. Price LC, Montani D, Tcherakian C, Dorfmüller P, Souza R, Gambaryan N, et al. Dexamethasone reverses monocrotalineinduced pulmonary arterial hypertension in rats. Eur Respir J 2011;37:813-22.

31. Rabinovitch M. Molecular pathogenesis of pulmonary arterial hypertension. J Clin Invest 2008;118:2372-9.

32. Tuder RM, Groves B, Badesch DB, Voelkel NF. Exuberant endothelial cell growth and elements of inflammation are present in plexiform lesions of pulmonary hypertension. Am J Pathol 1994;144:275-85.

33. Yao JS, Zhai W, Fan Y, Lawton MT, Barbaro NM, Young WL, et al. Interleukin-6 upregulates expression of KDR and stimulates proliferation of human cerebrovascular smooth muscle cells. J Cereb Blood Flow Metab 2007;27:510-20.

34. Cool CD, Kennedy D, Voelkel NF, Tuder RM. Pathogenesis and evolution of plexiform lesions in pulmonary hypertension associated with scleroderma and human immunodeficiency virus infection. Hum Pathol 1997;28:434-42.

35. Eddahibi S, Chaouat A, Tu L, Chouaid C, Weitzenblum E, Housset $B$, et al. Interleukin-6 gene polymorphism confers susceptibility to pulmonary hypertension in chronic obstructive pulmonary disease. Proc Am Thorac Soc 2006;3:475-6.

36. Yuan SM. Pulmonary artery hypertension in childhood: the transforming growth factor- $\beta$ superfamily-related genes. Pediatr Neonatol 2018;59:112-9.
37. Cogan J, Austin E, Hedges L, Womack B, West J, Loyd J, et al. Role of BMPR2 alternative splicing in heritable pulmonary arterial hypertension penetrance. Circulation 2012;126: 1907-16.

38. Morrell NW, Yang X, Upton PD, Jourdan KB, Morgan N, Sheares $K K$, et al. Altered growth responses of pulmonary artery smooth muscle cells from patients with primary pulmonary hypertension to transforming growth factor- $\beta_{1}$ and bone morphogenetic proteins. Circulation 2001;104:790-5.

39. Papapetropoulos A, Fulton D, Mahboubi K, Kalb RG, O'Connor DS, Li F, et al. Angiopoietin-1 inhibits endothelial cell apoptosis via the Akt/survivin pathway. J Biol Chem 2000;275:9102-5.

40. Kugathasan L. The protective role of the angiopoetin-1-tie2 system in transgenic models of pulmonary arterial hypertension (Advisor: Stewart DJ). https://tspace.library.utoronto.ca/bitstream/1807/24788/1/Kugathasan_Lakshmi_201006_PhD_thesis.pdf.

41. Yamamoto A, Takahashi H, Kojima Y, Tsuda Y, Morio Y, Muramatsu M, et al. Downregulation of angiopoietin-1 and Tie2 in chronic hypoxic pulmonary hypertension. Respiration 2008;75:328-38.

42. Genest J. C-reactive protein: risk factor, biomarker and/or therapeutic target? Can J Cardiol 2010;26(Suppl A): 41A-44A.

43. Kuribayashi T. Elimination half-lives of interleukin- 6 and cytokine-induced neutrophil chemoattractant-1 synthesized in response to inflammatory stimulation in rats. Lab Anim Res 2018;34:80-3.

44. Ershler WB, Sun WH, Binkley N. The role of interleukin- 6 in certain age-related diseases. Drugs Aging 1994;5:358-65.

45. Arita Y, Sakata Y, Sudo T, Maeda T, Matsuoka K, Tamai K, et al. The efficacy of tocilizumab in a patient with pulmonary arterial hypertension associated with Castleman's disease. Heart Vessels 2010;25:444-7.

46. Tcherakian C, Couderc LJ, Humbert M, Godot V, Sitbon O, Devillier P. Inflammatory mechanisms in HIV-associated pulmonary arterial hypertension. Semin Respir Crit Care Med 2013;34:645-53.

47. Chaouat A, Savale L, Chouaid C, Tu L, Sztrymf B, Canuet M, et al. Role for interleukin-6 in COPD-related pulmonary hypertension. Chest 2009;136:678-87. 